\title{
How geo-synthetic reinforcement supports piled embankment: a numerical approach
}

\author{
Young-Hoon Jung ${ }^{\mathrm{i})}$ and Taehee Lee ${ }^{\mathrm{ii})}$
}

i) Associate Professor, Department of Civil Engineering, Kyung Hee University, Yongin 17104, South Korea. ii) Ph.D. Student, Department of Civil Engineering, Kyung Hee University, Yongin 17104, South Korea

\begin{abstract}
In this study, the 3-dimensional piled embankment reinforced by geo-synthetics models have been developed to observe the difference geo-synthetic-supporting mechanism according to the changes of the spacing and number of the layers. The maximum tensile forces in the geo-synthetics and vertical stress distribution on the soft ground are obtained in each case to compare. When the spacing is increased, the maximum tensile forces transferred through the upper and lower layers become unbalanced. Until the spacing is $20 \mathrm{~cm}$, the greater tensile force acts on the upper layer. If the spacing is increased from $20 \mathrm{~cm}$ to $30 \mathrm{~cm}$, the tensile force in the upper layer is sharply decreased. It means the upper geo-synthetic would not receive the vertical stress sufficiently when the upper geo-synthetic placed on the unsuitable position. If the number of geo-synthetic layers are increased, the average tensile force is decreased. The number of geo-synthetics is more than the 4 layers, the imbalance of tensile forces in the each of geo-synthetics are significantly reduced and equalized
\end{abstract}

Keywords: geo-synthetic, piled embankment, numerical analysis, maximum tensile force

\section{INTRODUCTION}

Treating soft soil beneath the embankment structure is the one of the challenging tasks in the geotechnical engineering. In engineering practice, the geo-synthetic reinforced piled embankment has been used with its advantage of rapid and economic construction. To design the geo-synthetic reinforced piled embankment, it is necessary to separately calculate the loads applied to the pile, soft soil and geo-synthetics with extra care. In current design guidelines such as EBGEO (2010), BS 8006 (2010) and CUR 226 (2015), the different soil arching theories are used to separate the loads subjected on the pile and soft soil. In addition, the design guidelines have assumed a single layer of geo-synthetic regardless of its actual number. In practice, to prevent the reduction of geo-synthetic stiffness within the overlapped areas more than 2 layers of geo-synthetics are frequently installed. However, in case that the two or more layers of geo-synthetics are installed, there is no particular approaches to predict the loads in every geo-synthetics according to the spacing and number of layers.

In this study, the 3-dimensional piled-embankment numerical models with the inclusion of the geo-synthetics layers have been developed. To investigate the supporting mechanism of geo-synthetics with the different spacing and number of the geo-synthetics, the maximum tensile forces in the geo-synthetics and vertical stress distribution on the soft ground were computed

\section{NUMERICAL ANALYSIS}

The finite element analyses of piled embankment reinforced by geo-synthetics were conducted using commercial FEM program, ABAQUS (2006). As shown in Fig. 1, the numerical model was constructed based on the experimental condition performed at KRRI (Korea railway research Institute). In the test at KRRI, 16 steel model piles with $40 \mathrm{~cm}$ by $40 \mathrm{~cm}$ square steel top plate were arranged in a square pattern of the center-to-center distance of $1.2 \mathrm{~m}$. The poly-urethane foams representing the soft ground filled the space between the piles. Fill material of the embankment placed on the top surface of the piles and soft ground was placed was sequentially compacted until the height of the embankment became $2.55 \mathrm{~m}$. As shown in Fig. 1, by taking advantage of the repeated sectional geometry, the $1 / 4$ cross-section of the piled embankment was numerically modeled. The input parameters of the constitutive model of the embankment, soft ground and steel piles are summarized in Table 1 . The material properties of the embankment and poly-urethane foam were determined based on experimental data from preliminarily conducted triaxial and compression tests.

The membrane elements were employed to simulate the woven geotextiles used in the KRRI full-scale tests. 
Reminding that the geotextile has an in-plane shear stiffness of essentially zero (Perkins, 2000), two orthogonal tensile Young's moduli in the orthotropic elasticity for the membrane elements were only considered. Ignoring the ambiguity in the interfacial property between geo-synthetic layers and fill material, two opposite surfaces of the geosynthetics and fill material is simulated as fully bonded. Table 2 summarizes the material parameters of the orthotropic elasticity used in the geo-synthetics. In Table 2, $\mathrm{x}$ and $\mathrm{y}$ denotes the two orthogonal directions in plane. The numerical model used herein has been validated through the previous studies including Jung et al. (2016).

The upper and lower layer have identical material properties. The spacing between the surface of the pile cap and the lower layers of geo-synthetic is $0.15 \mathrm{~m}$ and the thickness of the fill between the lower and upper layers of geo-synthetic are varied from $0.1 \mathrm{~m}$ to $0.3 \mathrm{~m}$. Table 3 shows the material properties used in the analyses which are the number of the geo-synthetic layers are varied from 1 to 5 layers with $0.1 \mathrm{~m}$ of gaps among the geo-synthetics. The total stiffness of 400 $\mathrm{kN} / \mathrm{m}$ were equally distributed to the each of geo-synthetics. According to the number and spacing of the geo-synthetics, the maximum tensile force in each of geo-synthetics and the vertical stress distributions are observed.

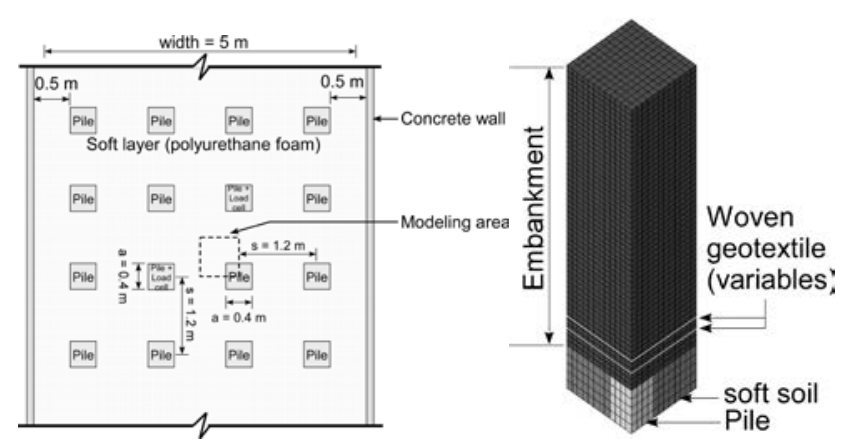

Fig. 1. Dimension of test and finite element mesh for simulations.

Table 1. Model parameters used in the numerical analysis.

\begin{tabular}{cccc}
\hline Component & Fill & Soft soil & Pile \\
\hline Material & Sand & Poly-urethane & Steel \\
\hline $\begin{array}{c}\text { Constitutive } \\
\text { model }\end{array}$ & $\begin{array}{c}\text { Linear elastic } \\
\text { and } \\
\text { Mohr-coulomb } \\
\text { plastic model }\end{array}$ & Linear elastic model \\
\hline Unit weight, $\gamma$ & $20 \mathrm{kN} / \mathrm{m}^{3}$ & $0.9 \mathrm{kN} / \mathrm{m}^{3}$ & $77 \mathrm{kN} / \mathrm{m}^{3}$ \\
\hline Poisson ration, $\mathrm{v}$ & 0.3 & 0.3 & 0.2 \\
\hline $\begin{array}{c}\text { Young's } \\
\text { modulus, } \mathrm{E}\end{array}$ & $80 \mathrm{MPa}$ & $40 \mathrm{kPa}$ & $200 \mathrm{GPa}$ \\
\hline Cohesion, c & $1 \mathrm{kPa}$ & - & - \\
\hline $\begin{array}{c}\text { Friction angle, } \\
\varphi\end{array}$ & 30 & - & - \\
\hline $\begin{array}{c}\text { Dilatancy angle, } \\
\psi\end{array}$ & 10 & - & - \\
\hline
\end{tabular}

Table 2 Material properties of geo-synthetics for the simulations with the different geo-synthetics spacing.

\begin{tabular}{cc}
\hline Thickness, $\mathrm{t}$ & $\mathrm{t}=2.5 \mathrm{~mm}$ \\
\hline Tensile stiffness, $\mathrm{J}$ & $\begin{array}{c}\mathrm{J}_{\mathrm{x}}=\mathrm{J}_{\mathrm{y}}=400 \mathrm{kN} / \mathrm{m} \\
\mathrm{E}_{\mathrm{x}}=\mathrm{E}_{\mathrm{y}}=\mathrm{J} / \mathrm{t}=160 \mathrm{MPa}\end{array}$ \\
\hline Shear stiffness, $\mathrm{G}$ & $\mathrm{G}_{\mathrm{xy}}=\mathrm{G}_{\mathrm{xz}}=\mathrm{G}_{\mathrm{yz}}=1 \mathrm{kPa}$ \\
\hline Poisson ratio, $\mathrm{v}$ & $\mathrm{V}_{\mathrm{xy}}=\mathrm{v}_{\mathrm{yx}}=0.3$ \\
\hline
\end{tabular}

Table 3 Material properties of geo-synthetics for the simulations with the different geo-synthetics spacing.

\begin{tabular}{lccccc}
\hline $\begin{array}{c}\text { The number of } \\
\text { layers }\end{array}$ & 1 & 2 & 3 & 4 & 5 \\
\hline $\begin{array}{c}\text { Tensile stiffness, } \\
\mathrm{J}\end{array}$ & $\begin{array}{c}400 \\
\mathrm{kN} / \mathrm{m}\end{array}$ & $\begin{array}{c}200 \\
\mathrm{kN} / \mathrm{m}\end{array}$ & $\begin{array}{c}133.333 \\
\mathrm{kN} / \mathrm{m}\end{array}$ & $\begin{array}{c}100 \\
\mathrm{kN} / \mathrm{m}\end{array}$ & $80 \mathrm{kN} / \mathrm{m}$ \\
\hline $\begin{array}{c}\text { Total tensile } \\
\text { stiffness }\end{array}$ & & & $400 \mathrm{kN} / \mathrm{m}$ & & \\
\hline
\end{tabular}

\section{NUMERICAL RESULTS AND DISCUSSIONS}

\subsection{Maximum tensile force in the geo-synthetics with different spacings}

Fig. 2 provides the variation of the maximum tensile forces in the upper and lower layers of geo-synthetic according to the changes of the geo-synthetic spacing. When the spacing between the geo-synthetics is zero, the tensile force is equally distributed in the numerical model. However, when the spacing is increased, the maximum tensile forces transferred through the upper and lower layers become unbalanced. Until the spacing is $20 \mathrm{~cm}$, the greater tensile force acts on the upper layer. If the spacing is bigger than $20 \mathrm{~cm}$, the lower layer is exerted by a greater tensile force. At the spacing of $25 \mathrm{~cm}$, the tensile forces applied to the upper and lower layers become rebalanced for a while. If the spacing is increased from $20 \mathrm{~cm}$ to $30 \mathrm{~cm}$, the tensile force in the upper layer is sharply decreased. This trend can be explained by the vertical stress redistribution induced by the soil arching effect.

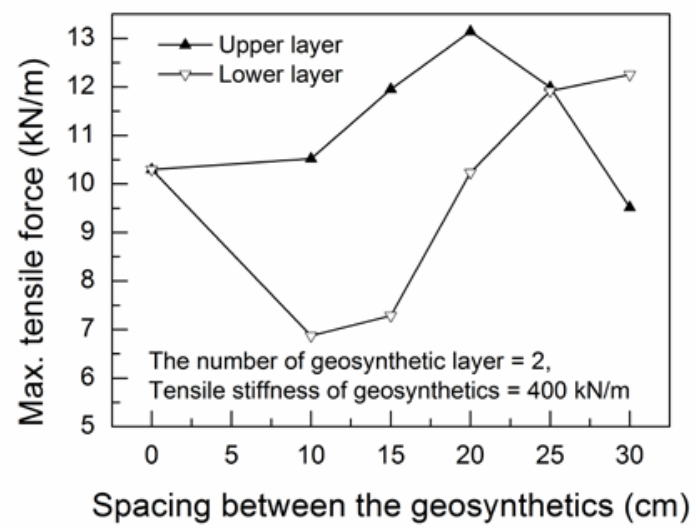

Fig. 2. Maximum tensile force according to the changes of the geo-synthetic spacing.

Fig. 3 shows the vertical stress distributions on the center of the soft ground with the fill height. If the piles and soft ground have the equivalent stiffness, vertical stress on the any supporting places linearly increases like dotted-line. In the pile-supported embankment, 
however, the major part of the fill load and surcharge are concentrated onto the piles. Simultaneously, the vertical stress on the soft soil would be suddenly reduced at the certain depth of embankment as shown Fig. 3. Below the depth of initiating the vertical stress decreasing on the soft ground, the vertical stress changes depending on the location. Therefore, the tensile force in the geo-synthetics would be changed according to the position of the geo-synthetics installation. In case of the spacing is zero, geo-synthetics are placed on the suitable position to resist the vertical stress. With 10 and $20 \mathrm{~cm}$ of geo-synthetic spacing, the upper layer plays their own role. However, when the spacing is $30 \mathrm{~cm}$, the height of geo-synthetic installation meets the position occurring the minimum vertical stress. In this case, the upper geo-synthetic would not receive the vertical stress sufficiently. Therefore, the geo-synthetics placed on the unsuitable position is made unnecessary.
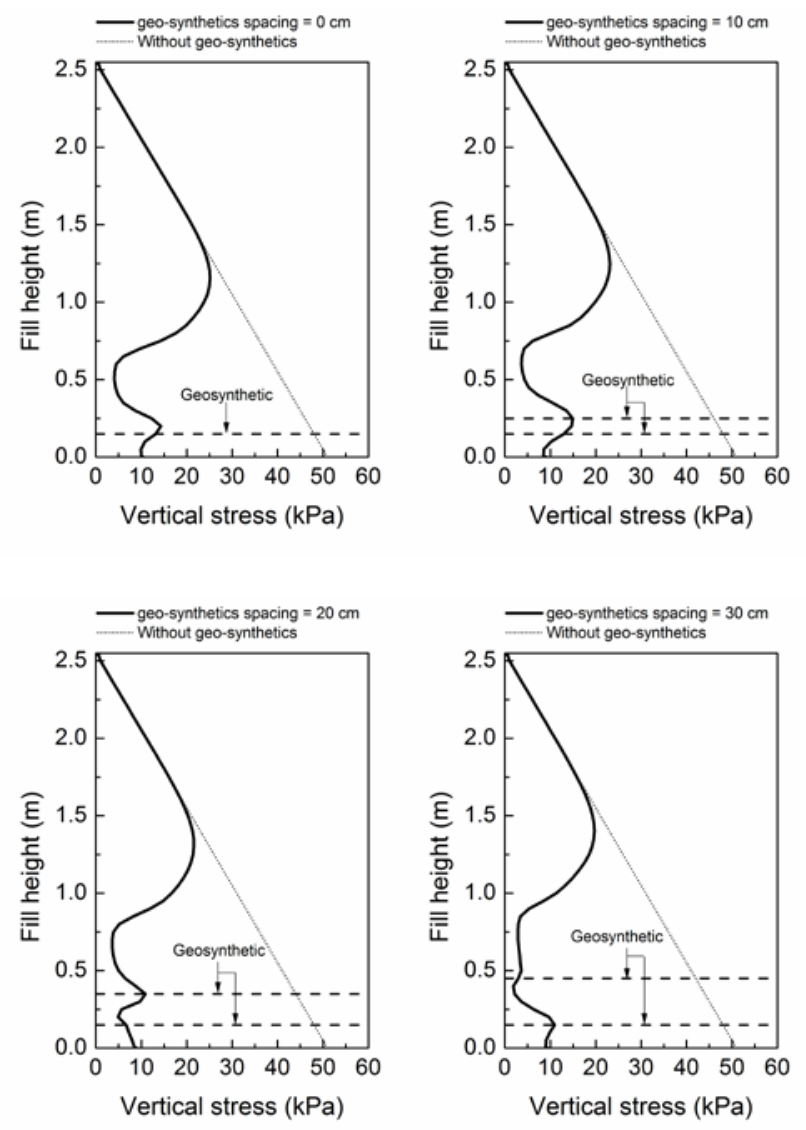

Fig. 3. Vertical stress distributions in the embankments according to the geo-synthetics spacing.

\subsection{Maximum tensile force in the geo-synthetics according to the number of layers}

Fig. 4 shows the maximum tensile forces in the geo-synthetics according to the number of layers. As shown Fig. 4, although the tensile stiffness of geo-synthetics tends to be reduced with the increase of the number of layers to provide all simulations with the equivalent tensile stiffness, the average tensile force presented by dotted-line is decreased. In all cases excluding 5 layers of geo-synthetics applied, the most tensile force appears in the top layer. If the 5 layers are applied, the 2 lowest layers charge the rather large tensile forces. In case 2 and 3 layers of geo-synthetics are installed, the most tensile forces are transferred to the top layer. At the same time, the tensile forces in the other lower layers are relatively smaller than in the top layer. Therefore, the imbalance of tensile force appears clearly. However, the number of geo-synthetics is more than the 4 layers, the difference of tensile force in the each of geo-synthetics are significantly reduced.

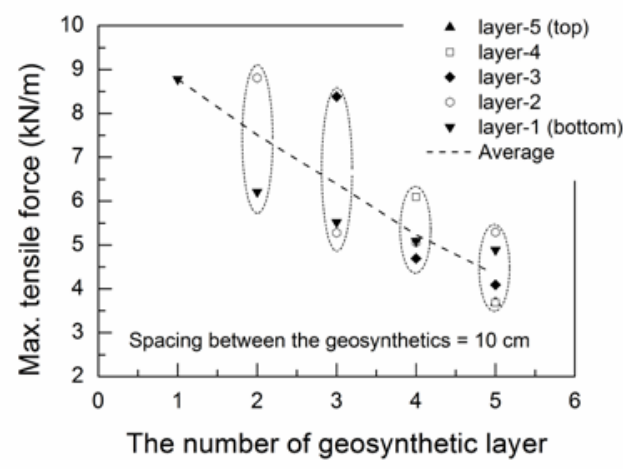

Fig. 4. Maximum tensile force according to the changes of the number of geo-synthetic layers.
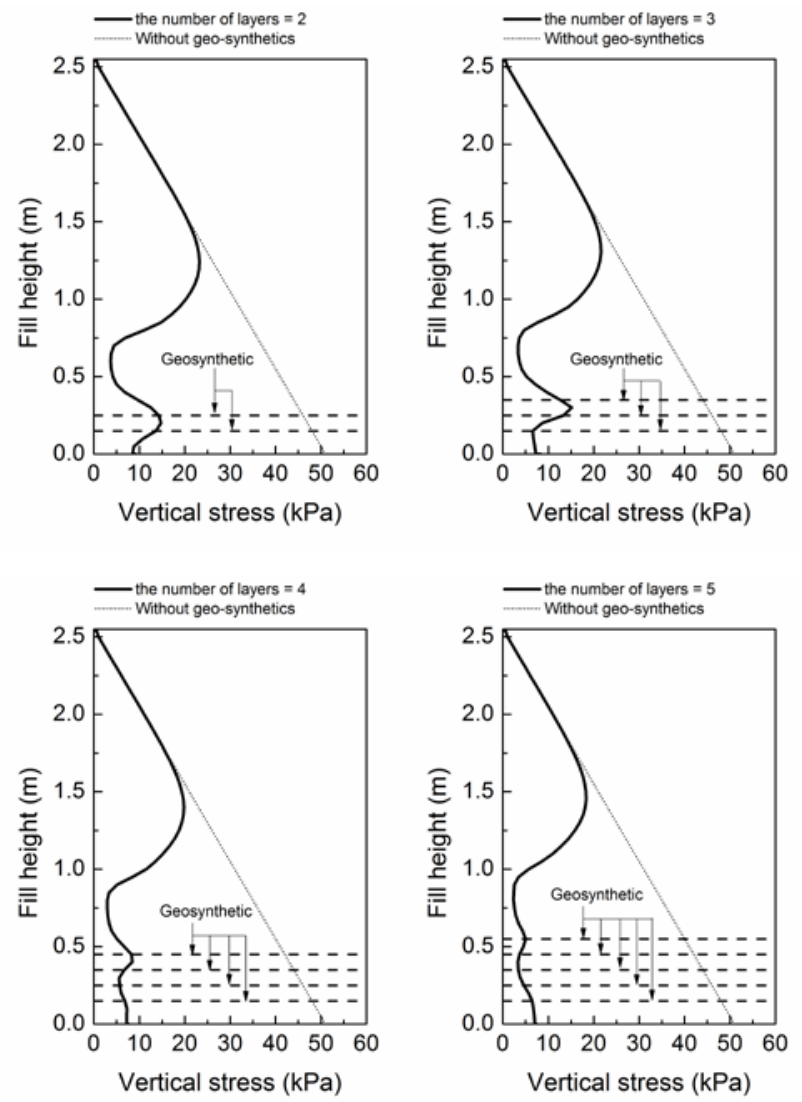

Fig. 5. Vertical stress distributions in the embankments according to the number of layers. 
Fig. 5 demonstrates the vertical stress distribution of embankment on the center of the soft ground according to the number of the geo-synthetics. The analyzing results of 2 layers of geo-synthetic are similar with Fig. 3 . When a geo-synthetic is added, the peak of vertical stress near the geo-synthetic installed becomes more remarkable. However, when more than 4-layers of geo-synthetics are applied, the vertical stress distribution becomes more and more slowly. Therefore, the maximum tensile forces applied in the 4 or 5 layers are equalized as shown Fig. 4.

\section{CONCLUSIONS}

In this study, the maximum tensile forces and vertical stress distribution of the embankment on the center of the soft ground were numerically investigated. The spacing of two layers of geo-synthetic and number of layers with equivalent gaps were varied in the simulations. In case that the gap between two layers of geo-synthetics are changed, the different distribution of the tensile force between layers was observed. In addition, when the upper geo-synthetic placed on the unsuitable position to charge the vertical stress sufficiently, the effect of geo-synthetics becomes diminished. When the number of geo-synthetic layers are increased, the average tensile force is decreased. In case that two or three layers of geo-synthetics are installed, the differences in tensile forces became obvious. When the number of geo-synthetics is more than four, the difference of tensile forces in the each of geo-synthetics became significantly reduced.

\section{ACKNOWLEDGEMENTS}

This research was supported by a grant (Development of settlement restrain method to substitute the bridge on soft ground, 15RTRP-B067919-03) from Railroad Technology Research Program funded by Ministry of Land, Infrastructure and Transport of Korean government.

\section{REFERENCES}

1) BS 8006 (2010): Code of practice for strengthened/reinforced soils and other fills, British standards institution.

2) CUR 226 (2015), Design Guideline Piled Embankments (in Dutch).

3) EBGEO (2010), Recommendations for Design and Analysis of Earth Structures using Geosynthetic Reinforcements, German Geotechnical Society.

4) Jung, Y.-H., Lee, T., Lee S.-H., Lee, I.-W. and Kim, T. (2016): Finite element investigation on patterns of soil arching in geosynthetics-reinforced piled embankment, Geotechnical and Structural Engineering Congress 2016, Phoenix, USA, 329-338.

5) Perkins, S. W. (2000): Constitutive modeling of geosynthetics. Geotextiles and Geomembranes, 18(5), 273-292. 